\title{
KARAKTERISTIK PEMBAKARAN BRIKET ARANG BERBAHAN BAKU SAMPAH KOTA DENGAN ANALISA TERMOGRAVIMETRY
}

\author{
Yudi Setiawan \\ Jurusan Teknik Mesin, Universitas Bangka Belitung \\ Jl.Merdeka no. 04 Pangkalpinang \\ E-mail : yudiubb@yahoo.co.id
}

\begin{abstract}
Abstrak :Penelitian ini bertujuan untuk mengetahui pengaruh campuran bahan terhadap char yang dihasilkan, energi aktivasi dan karakteristik pembakarannya (ITVM, ITFC, PT dan BT). Proses pirolisis menggunakan 6 sampel uji yaitu benda uji 1 (100\% bambu), benda uji 2 (100\% daun pisang), benda uji 3 (100\% plastik kemasan), benda uji 4 (50\% bambu-50\% daun pisang), benda uji 5 ( $50 \%$ bambu-50\% plastik kemasan) dan benda uji 6 (50\% daun pisang-50\% plastik kemasan) dengan massa 20 gram. Sampel dipirolisis dengan temperatur akhir $400{ }^{\circ} \mathrm{C}$ dengan heating rate $10^{\circ} \mathrm{C} / \mathrm{menit}$. Temperatur dipertahankan selama 30 menit setelah temperatur sampel mencapai temperatur akhir yang diinginkan. Setelah char hasil pirolisis diperoleh kemudian dilakukan pembriketan sebelum pembakaran. Bahan briket memiliki massa 3 gram, yang terdiri dari 2,4 gram arang (80\%) dan 0,6 gram binder (2,86\% kanji dan $17,14 \%$ air).

Untuk bahan tunggal benda uji 2 (daun pisang) menghasilkan massa akhir pirolisis tertinggi yaitu 32,8\% dengan nilai kalor $3.982 \mathrm{kal} /$ gram.Variasi campuran bahan berpengaruh terhadap massa char yang dihasilkan. Campuran bahan uji 4 (bambu-daun pisang) menghasilkan massa akhir pirolisis tertinggi yaitu 30,3\% dengan nilai kalor $5.547 \mathrm{kal} /$ gram. Nilai kalor tertinggi dihasilkan pada campuran benda uji 6 (daun pisang-plastik kemasan) yaitu $8.360 \mathrm{kal} /$ gram yang kemungkinan disebabkan oleh uap tar yang terkandung dalam volatile matter akan menjadi reaktif. Uap tar dapat mengalami reaksi sekunder berupa cracking menjadi gas-gas hidrokarbon yang terperangkap di dalam pori-pori partikel arang atau mengalami repolimerisasi menjadi arang. Untuk bahan campuran, benda uji 4 (bambudaun pisang) memiliki energi aktivasi terendah yaitu 22,923 (kJ/mol).Karakteristik pembakaran pada benda uji 4yaitu ITVM $=158^{\circ} \mathrm{C}$, ITFC $=176^{\circ} \mathrm{C}, \mathrm{PT}=376^{\circ} \mathrm{C}$ dan $\mathrm{BT}=729^{\circ} \mathrm{C}$.
\end{abstract}

Kata kunci : pirolisis, char, thermogravimetry

\section{Pendahuluan}

Konsumsi energi di berbagai sektor seperti transportasi, industri dan energi listrik untuk rumah tangga di Indonesia tercatat terus meningkat dengan laju pertumbuhan rata-rata pertahun sebesar $5,2 \%$, sebaliknya cadangan energi nasional yang semakin menipis menimbulkan kekhawatiran akan krisis energi di masa mendatang jika tidak 
ditemukan sumber-sumber energi yang baru. Beberapa peneliti telah melakukan percobaan pada beberapa jenis biomassa untuk mengetahui pengaruh pirolisis terhadap karakteristik biomassa. Grammelis dkk (2009) melakukan penelitian dengan sampel 5 sampel berbahan baku kayu, 6 sampel berbahan baku plastik dan 2 sampel $R D F$ (Refused Derived Fuel). Pirolisis dilakukan pada kisaran temperatur 30 ${ }^{0} \mathrm{C}$ sampai dengan $1000{ }^{0} \mathrm{C}$ dengan laju kenaikan temperatur $20{ }^{0} \mathrm{C} /$ menit, sementara proses pembakaran dilakukan dengan kondisi termal yang sama. Hasil penelitian menunjukkan bahwa kinetika reaksi dekomposisi $R D F$ merupakan penjumlahan dari kinetika komponen penyusunnya dan juga RDF dengan komponen plastik yang lebih tinggi menghasilkan char yang lebih rendah dengan reaktivitas yang rendah. Ojolo dan Bamgboye (2005) telah melakukan penelitian terhadap sampel sampah (campuran dari limbah makanan, buahbuahan/sayur, kertas, plastik dan bahan tekstil) melalui proses pirolisis untuk mendapatkan tar, char dan gas. Pada penelitiannyaberat sampel yang digunakan seberat $12 \mathrm{~kg}$ dengan temperatur pirolisis berkisar antara 500 ${ }^{0} \mathrm{C}$ dan $650{ }^{0} \mathrm{C}$, perbandingan produk yang didapatkan dari penelitian tersebut adalah 52,2\% tar, 25,2\% char dan 22,6 $\%$ gas. Phan dkk (2008) telah meneliti karakteristik produk pirolisis dari segregated waste dimana proses pirolisis berlangsung dengan sampel 200 gram dan dengan kisaran temperatur akhir $350{ }^{\circ} \mathrm{C}$ sampai dengan $700{ }^{\circ} \mathrm{C}$. Hasilnya produk char yang dihasilkan 38\%-55\% dimana nilai kalor produk liquid berkisar antara 10-12 MJ/kg. Saptoadi (2006) meneliti ukuran partikel terhadap laju pembakaran briket. Hasilnya diperoleh bahwa semakin kecil ukuran partikel akan menurunkan laju pembakaran briket dari sekam padi, hal ini disebabkan oleh densitas briket yang semakin tinggi sehingga porositas menjadi lebih rendah dan difusi menjadi terhambat. Zapusek dkk (2003) melakukan penelitian mengenai pengaruh temperatur, lama dan ukuran partikel dalam proses karbonasi terhadap sifat-sifat dasar batubara setelah dikarbonasi. Pada variasi ukuran partikel batubara yang digunakan pada temperatur $750{ }^{0} \mathrm{C}$ selama 30 menit menunjukkan semakin besar ukuran partikel dapat meningkatkan kandungan air, karbon, kalori dan hidrogen. Tetapi dapat menurunkan kandungan abu, zat volatil, 
nitrogen dan sulfur. Gran (2001) persamaan laju reaksi (k) yang merupakan representasi dari konstanta Arrhenius $\left(k=A e^{-E / R T}\right)$ dengan $A$ adalah faktor pra eksponensial, $E$ adalah energi aktivasi, $\bar{R}$ adalah konstanta gas universal, $T$ adalah temperatur. Thermogravimetry Analysis (TGA) merupakan suatu teknik untuk menganalisa perhitungan stabilitas termal suatu bahan dengan memonitor perubahan massa selama spesimen diberi perlakuan panas. Grafik perubahan massa ditampilkan sebagai fungsi terhadap kenaikan temperatur dapat dilihat pada gambar 1 .

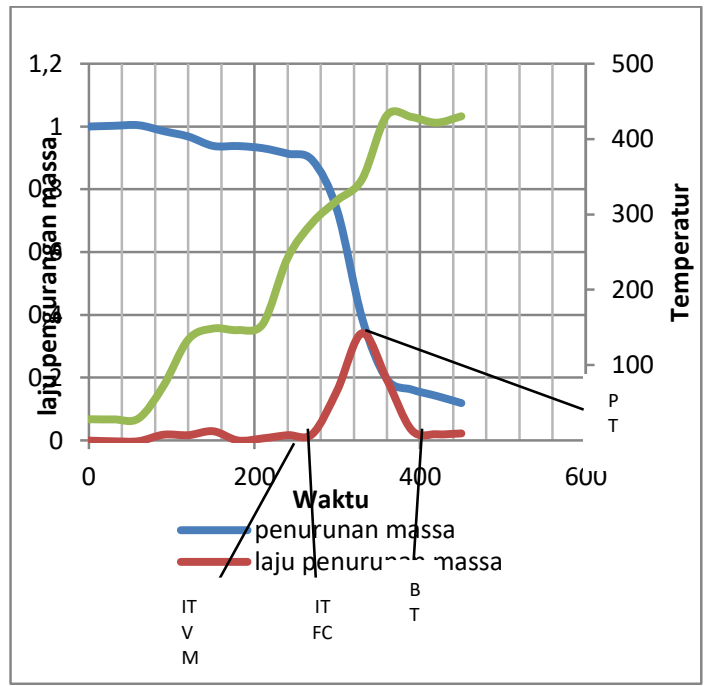

Gambar 1. Proses pembakaran

\section{Initiation Temperature of Volatile}

Matter (ITVM) adalah temperatur saat mulai terbakarnya volatile matter. Intiation Temperature of Fixed Carbon (ITFC) adalah temperatur saat mulai terbakarnya fixed carbon. Peak of weight loss rate Temperature (PT) adalah temperatur saat laju pengurangan massa tertinggi. Burning out Temperature (BT) adalah temperatur saat fixed carbon telah habis terbakar.

\section{Metodologi Penelitian}

Gambar 2. Skema peralatan uji pirolisis

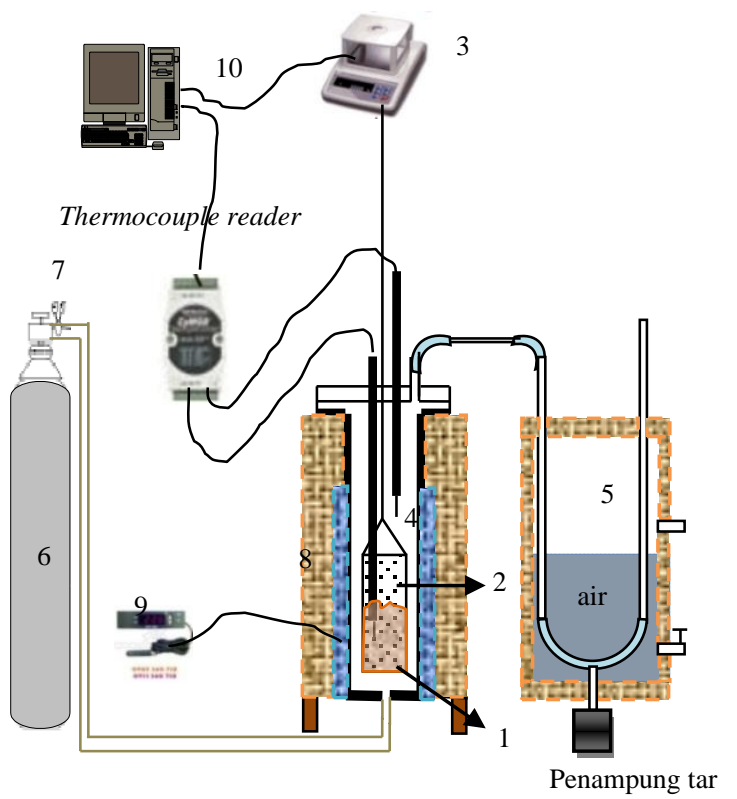

Pada gambar 2 proses pirolisis menggunakan sampel uji dengan massa 20 gram (1) dimasukkan ke dalam wadah sampel (2), yang digantungkan dengan kawat pada timbangan digital (3). Salah satu ujung thermocouple (4) diletakkan sedikit di atas sampel dan ujung thermocouple yang lain tertanam dalam sampel tetapi sedikit di atas pada bagian bawah wadah sampel. Bak 
pendingin (5) diisi air. Nitrogen dialirkan dari tabung (6) dengan laju aliran 1 liter/menit menggunakan pengaturan rotameter (7). Furnace (8) dipanaskan dengan menghidupkan thermocontroller (9) untuk memperoleh temperatur akhir $400{ }^{\circ} \mathrm{C}$ dengan heating rate $\quad 10^{\circ} \mathrm{C} /$ menit. Temperatur dipertahankan selama 30 menit setelah temperatur sampel mencapai temperatur akhir yang diinginkan. Laju pengurangan massa dan data temperatur terekam di program komputer (10). Setelah char hasil pirolisis diperoleh kemudian dilakukan pembriketan sebelum pembakaran. Bahan briket memiliki massa 3 gram, yang terdiri dari 2,4 gram arang (80\%) dan 0,6 gram binder (2,86\% kanji dan 17,14\% air). Bahan tersebut dicetak dengan cetakan berbentuk silinder dan berdiameter 15 mm. Pembriketan dilakukan pada tekanan $250 \mathrm{~kg} / \mathrm{cm}^{2}$ selama 5 menit, setelah itu briket dipanaskan dalam oven pemanas pada temperatur $100{ }^{\circ} \mathrm{C}$ selama 20 menit untuk mengurangi kadar air. Pembakaran briket dilakukan dengan cara menaikkan temperatur ruang bakar secara bertahap dengan besar kenaikan konstan tiap waktu (kenaikan temperatur $20{ }^{0} \mathrm{C} /$ menit) sampai tersisa abu.

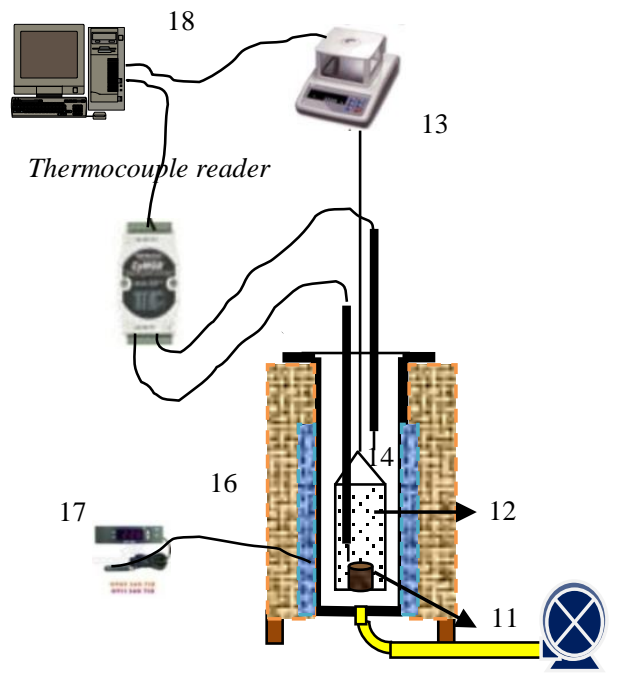

Gambar 3 Skema peralatansuji pembakaran

Pada gambar 3 proses uji pembakaran, sampel briket (11) dimasukkan ke dalam wadah sampel (12) yang digantungkan pada timbangan digital (13). Salah satu ujung thermocouple (14) diletakkan sedikit di atas sampel dan ujung thermocouple lain tepat di atas sampel. Blower (15) mengalirkan udara dengan laju aliran udara $0,1 \mathrm{~m} / \mathrm{s}$. Furnace (16) dipanaskan dengan menghidupkan thermocontroller (17) untuk mengatur heating rate $20^{\circ} \mathrm{C} /$ menit. Laju pengurangan massa dan data temperatur terekam pada program komputer (18).

\section{Hasil dan Pembahasan}

\subsection{Hasil Pengujian Nilai Kalor}

Pengujian uji proksimat pada bahan tanpa pirolisis diperoleh hasil seperti tabel 1 berikut : 
Tabel 1. Hasil uji proksimat bahan mentah

Dari uji proksimat terlihat bahwa kadar fixed carbon lebih tinggi terdapat pada bahan plastik kemasan. Kenaikan nilai kalor dipengaruhi oleh volatile matter dan fixed carbon sedangkan penurunan nilai kalor dapat disebabkan oleh kadar abu dan kadar air yang tinggi .

\subsection{Pengaruh Variasi Campuran}

Terhadap Massa Arang Serta Nilai

Kalor

Data lengkap pengujian pirolisis terhadap massa arang dan nilai kalor dapat dilihat pada tabel sebagai berikut:

\begin{tabular}{|c|c|c|c|}
\hline $\begin{array}{c}\text { Nomor } \\
\text { Benda } \\
\text { Uji }\end{array}$ & $\begin{array}{c}\text { Temperatur } \\
\text { pengurangan } \\
\text { massa } \\
\left({ }^{\circ} \mathrm{C}\right)\end{array}$ & $\begin{array}{c}\text { Massa } \\
\text { char } \\
(\%)\end{array}$ & $\begin{array}{c}\text { Nilai kalor } \\
(\mathrm{kal} / \text { gram })\end{array}$ \\
\hline 1 & $183-398$ & 27,63 & 6.215 \\
\hline 2 & $173-402$ & 32,8 & 3.982 \\
\hline 3 & $290-412$ & 15,2 & 5.649 \\
\hline 4 & $136-395$ & 30,3 & 5.547 \\
\hline 5 & $132-399$ & 25,1 & 4.913 \\
\hline 6 & $130-412$ & 24,2 & 8.360 \\
\hline
\end{tabular}

Tabel 2. Massa char dan Nilai kalor

Pada penelitian campuran massa char terbanyak terdapat pada bahan bambudaun pisang, ini mungkin di sebabkan komponen bahan organik memiliki fixed carbon yang lebih tinggi dari pada bahan anorganik. Sedangkan nilai kalor tertinggi terdapat pada bahan daun pisang-plastik kemasan, hal ini mungkin disebabkan oleh uap tar yang terkandung dalam volatile matter akan menjadi reaktif. Uap tar dapat mengalami reaksi sekunder berupa cracking menjadi gas-gas hidrokarbon yang terperangkap di dalam pori-pori partikel arang atau mengalami repolimerisasi menjadi arang (Di Blasi, 2008), sehingga hal inilah yang diduga memberi kontribusi terhadap peningkatan nilai kalor. Proses reaksi sekunder dari uap tar tersebut diilustrasikan pada gambar.

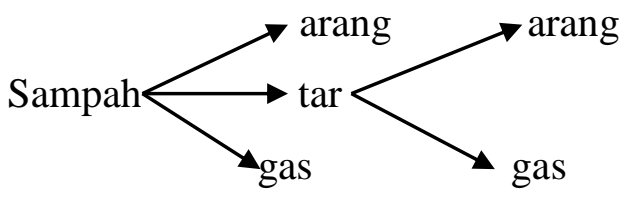

\begin{tabular}{|l|c|c|c|c|c|}
\hline $\begin{array}{l}\text { Baha } \\
\mathrm{n}\end{array}$ & $\begin{array}{c}\text { abu } \\
(\%)\end{array}$ & $\begin{array}{c}\text { Kad } \\
\text { ar } \\
\text { air } \\
(\%)\end{array}$ & $\begin{array}{c}\text { volat } \\
\text { ile } \\
\text { matt } \\
\text { er } \\
(\%)\end{array}$ & $\begin{array}{c}\text { kar } \\
\text { bon } \\
\text { teta } \\
\text { p } \\
(\%)\end{array}$ & $\begin{array}{c}\text { Nilai kalor } \\
(\mathrm{kal} / \\
\text { gram })\end{array}$ \\
\hline $\begin{array}{l}\text { Bam } \\
\text { bu }\end{array}$ & $\begin{array}{c}8,0 \\
05\end{array}$ & $\begin{array}{c}7,3 \\
15\end{array}$ & $\begin{array}{c}80,3 \\
76\end{array}$ & $\begin{array}{c}4,3 \\
04\end{array}$ & $4.001,563$ \\
\hline $\begin{array}{l}\text { Dau } \\
\text { nisa } \\
\text { pis } \\
\text { ng }\end{array}$ & 13, & 10, & 73,0 & 3,2 & $4.189,169$ \\
\hline $\begin{array}{l}\text { Plast } \\
\text { ik } \\
\text { kem } \\
\text { asan }\end{array}$ & 1,8 & 0,9 & 95,5 & 1,6 & $8.326,184$ \\
& 1 & 55 & 45 & 9 & \\
\hline
\end{tabular}

Gambar 3. Reaksi sekunder uap tar

\section{3. Karakteristik Pembakaran}


- Karakteristik Pembakaran

\section{Benda Uji 1}

Pengurangan massa akibat mulai terbakarnya volatile matter terjadi pada suhu sekitar $203{ }^{\circ} \mathrm{C}$. Pengurangan massa akibat mulai terbakarnya fixed carbon terjadi pada suhu sekitar 248 ${ }^{\circ} \mathrm{C}$. Pengurangan massa tertinggi pada suhu sekitar $364^{\circ} \mathrm{C}$. Fixed carbon habis terbakar terjadi pada suhu sekitar $737^{\circ} \mathrm{C}$ dengan energi aktivasi $22,981 \mathrm{~kJ} / \mathrm{mol}$. Pada akhir pembakaran diperoleh massa akhir 18,1 \% dan waktu pembakaran sekitar 23 menit.

Tabel 3. Karakteristik dan energi aktivasi pembakaran bambu

\begin{tabular}{|c|c|c|c|c|c|}
\hline \multirow[t]{2}{*}{ Bahan } & \multicolumn{4}{|c|}{$\begin{array}{l}\text { Karakteristik temperatur } \\
\text { pembakaran } \\
\left({ }^{\circ} \mathrm{C}\right)\end{array}$} & \multirow{2}{*}{$\begin{array}{l}\text { Energi } \\
\text { aktivas } \\
\mathrm{i}(\mathrm{kJ} / \\
\mathrm{mol})\end{array}$} \\
\hline & $\begin{array}{c}\text { ITV } \\
\text { M }\end{array}$ & $\begin{array}{c}\text { ITF } \\
\text { C }\end{array}$ & PT & BT & \\
\hline $\begin{array}{c}\text { Benda } \\
\text { Uji } 1\end{array}$ & 203 & 248 & 364 & 737 & 22,981 \\
\hline
\end{tabular}

- Karakteristik Pembakaran Benda Uji 2

Pengurangan massa akibat mulai terbakarnya volatile matter terjadi pada suhu sekitar $197{ }^{\circ}$ C.Pengurangan massa akibat mulai terbakarnya fixed carbon terjadi pada suhu sekitar 209 ${ }^{\circ} \mathrm{C}$. Pengurangan massa tertinggi pada suhu sekitar $315{ }^{\circ} \mathrm{C}$ dan fixed carbon habis terbakar terjadi pada suhu sekitar
$736{ }^{\circ} \mathrm{C}$ dengan energi aktivasi pembakaran 22,623 kJ/mol. Pada akhir pembakaran diperoleh massa akhir 16,5 $\%$ dengan waktu pembakaran sekitar 21 menit.

Tabel 4. Karakteristik dan energi aktivasi pembakaran daun pisang

\begin{tabular}{|c|c|c|c|c|c|}
\hline \multirow{2}{*}{ Bahan } & \multicolumn{4}{|c|}{$\begin{array}{c}\text { Karakteristik temperatur } \\
\text { pembakaran } \\
\left({ }^{\circ} \mathrm{C}\right)\end{array}$} & $\begin{array}{c}\text { Energi } \\
\text { aktivasi } \\
(\mathrm{kJ} /\end{array}$ \\
& \multicolumn{4}{|c|}{ mol $)$} \\
\cline { 2 - 5 } & $\begin{array}{c}\text { ITV } \\
\mathrm{M}\end{array}$ & ITFC & PT & BT & \\
\hline $\begin{array}{c}\text { Benda } \\
\text { Uji 2 }\end{array}$ & 197 & 209 & 315 & 736 & 22,623 \\
\hline
\end{tabular}

- Karakteristik Pembakaran

\section{Benda Uji 3}

Pengurangan massa akibat mulai terbakarnya volatile matter terjadi pada suhu sekitar $242^{\circ} \mathrm{C}$. Pengurangan massa akibat mulai terbakarnya fixed carbon terjadi pada suhu sekitar $288^{\circ} \mathrm{C}$. Pengurangan massa tertinggi pada suhu sekitar $687^{\circ} \mathrm{C}$ dan fixed carbon habis terbakar terjadi pada suhu sekitar $559^{\circ} \mathrm{C}$. Pada akhir pembakaran diperoleh massa akhir $51 \%$ dengan waktu pembakaran sekitar 10 menit dengan energi aktivasi pembakaran $31,420 \mathrm{~kJ} / \mathrm{mol}$. Dari grafik-grafik di atas dapat diketahui temperatur, energi aktivasi dan waktu pembakaran seperti dalam tabel berikut 
Tabel 5. Karakteristik dan energi aktivasi pembakaran plastik kemasan

\begin{tabular}{|c|c|c|c|c|c|}
\hline \multirow{4}{*}{ Bahan } & \multicolumn{4}{|c|}{$\begin{array}{c}\text { Karakteristik temperatur } \\
\text { pembakaran } \\
\left({ }^{\circ} \mathrm{C}\right)\end{array}$} & $\begin{array}{c}\text { Energi } \\
\text { aktivas } \\
\text { i (kJ/ } \\
\text { mol) }\end{array}$ \\
\cline { 2 - 5 } & $\begin{array}{c}\text { ITV } \\
\text { M }\end{array}$ & $\begin{array}{c}\text { ITF } \\
\text { C }\end{array}$ & PT & BT & mel \\
\hline $\begin{array}{c}\text { Benda } \\
\text { Uji 3 }\end{array}$ & 242 & 248 & 687 & 559 & 31,420 \\
\hline
\end{tabular}

\section{- Karakteristik Pembakaran}

\section{Benda Uji 4}

Pengurangan massa akibat mulai terbakarnya volatile matter terjadi pada suhu sekitar $158{ }^{\circ} \mathrm{C}$. Pengurangan massa akibat mulai terbakarnya fixed carbon terjadi pada suhu sekitar $176^{\circ} \mathrm{C}$. Pengurangan massa tertinggi pada suhu sekitar $376{ }^{\circ} \mathrm{C}$ dan fixed carbon habis terbakar terjadi pada suhu sekitar 729 ${ }^{\circ} \mathrm{C}$. Pada akhir pembakaran diperoleh massa akhir $28 \%$ dengan waktu pembakaran sekitar 18 menit dan energi aktivasi pembakaran 22,923 kJ/mol.

Tabel 6. Karakteristik dan energi aktivasi pembakaran bambu-daun pisang

\begin{tabular}{|c|c|c|c|c|c|}
\hline \multirow{3}{*}{ Bahan } & \multicolumn{4}{|c|}{$\begin{array}{c}\text { Karakteristik temperatur } \\
\text { pembakaran } \\
\left({ }^{\circ} \mathrm{C}\right)\end{array}$} & $\begin{array}{c}\text { Energi } \\
\text { aktivasi } \\
(\mathrm{kJ} / \mathrm{mol})\end{array}$ \\
\cline { 2 - 5 } & $\begin{array}{c}\text { ITV } \\
\mathrm{M}\end{array}$ & ITFC & PT & BT & \\
\hline Benda Uji 4 & 158 & 176 & 376 & 729 & 22,923 \\
\hline
\end{tabular}

- Karakteristik Pembakaran

\section{Benda Uji 5}

Pengurangan massa akibat mulai terbakarnya volatile matter terjadi pada suhu sekitar $174^{\circ} \mathrm{C}$. Pengurangan massa akibat mulai terbakarnya fixed carbon terjadi pada suhu sekitar $194{ }^{\circ} \mathrm{C}$. Pengurangan massa tertinggi pada suhu sekitar $384,3{ }^{\circ} \mathrm{C}$ dan fixed carbon habis terbakar terjadi pada suhu sekitar $602{ }^{\circ} \mathrm{C}$. Pada akhir pembakaran diperoleh massa akhir 20,1 \% dengan waktu pembakaran 18 menit dan energi aktivasi pembakaran 26,265 kJ/mol.

Tabel 7. Karakteristik dan energi aktivasi pembakaran bambuplastik kemasan

\begin{tabular}{|c|c|c|c|c|c|}
\hline \multirow{2}{*}{ Bahan } & \multicolumn{3}{|c|}{$\begin{array}{c}\text { Karakteristik temperatur } \\
\text { pembakaran } \\
\left({ }^{\circ} \mathrm{C}\right)\end{array}$} & $\begin{array}{c}\text { Energi } \\
\text { aktivasi } \\
(\mathrm{kJ} / \mathrm{mol})\end{array}$ \\
\cline { 2 - 5 } & $\begin{array}{c}\text { ITV } \\
\mathrm{M}\end{array}$ & ITFC & PT & BT & \\
\hline $\begin{array}{c}\text { Benda Uji } \\
5\end{array}$ & 174 & 194 & 384 & 602 & 26,265 \\
\hline
\end{tabular}

- Karakteristik Pembakaran Benda Uji 6

Pengurangan massa akibat mulai terbakarnya volatile matter terjadi pada suhu sekitar $193{ }^{\circ} \mathrm{C}$. Pengurangan massa akibat mulai terbakarnya fixed carbon terjadi pada suhu sekitar $240{ }^{\circ} \mathrm{C}$. Pengurangan massa tertinggi pada suhu sekitar $420{ }^{\circ} \mathrm{C}$ dan fixed carbon habis terbakar terjadi pada suhu sekitar 574 ${ }^{\circ} \mathrm{C}$. Pada akhir pembakaran diperoleh massa akhir $42 \%$ dengan waktu pembakaran sekitar 42 menit dengan 
energi aktivasi pembakaran 32,809

$\mathrm{kJ} / \mathrm{mol}$.

Tabel 8. Karakteristik dan energi aktivasi pembakaran daun pisangplastik kemasan

\begin{tabular}{|c|c|c|c|c|c|}
\hline \multirow{2}{*}{ Bahan } & \multicolumn{4}{|c|}{$\begin{array}{c}\text { Karakteristik temperatur } \\
\text { pembakaran } \\
\left({ }^{\circ} \mathrm{C}\right)\end{array}$} & $\begin{array}{c}\text { Energi } \\
\text { aktivasi } \\
(\mathrm{kJ} / \\
\text { mol })\end{array}$ \\
& \multicolumn{4}{|c|}{} & \\
\cline { 2 - 5 } & $\begin{array}{c}\text { ITV } \\
\mathrm{M}\end{array}$ & ITFC & PT & BT & \\
\hline $\begin{array}{c}\text { Benda Uji } \\
6\end{array}$ & 193 & 240 & 420 & 574 & 32,809 \\
\hline
\end{tabular}

Pada proses pembakaran, bahan - bahan campuran akan mengalami proses terbakarnya volatile matter lebih awal (temperatur lebih rendah). Kejadian ini mungkin disebabkan oleh sifat bahan yang tidak homogen sehingga memungkinkan terjadinya porositas yang berakibat pada semakin cepatnya volatile matter terbakar

\section{Kesimpulan}

Untuk bahan tunggal, benda uji 2 (daun pisang) menghasilkan massa akhir pirolisis tertinggi yaitu $32,8 \%$ dengan nilai kalor $3.982 \mathrm{kal} / \mathrm{gram}$. Untuk bahan campuran, benda uji 4 (bambu daun pisang) menghasilkan massa akhir pirolisis tertinggi yaitu 30,3\% dengan nilai kalor $5.547 \mathrm{kal} /$ gram. Nilai kalor tertinggi dihasilkan pada campuran benda uji 6 (daun pisang - plastik kemasan) yaitu $8.360 \mathrm{kal} /$ gram yang kemungkinan disebabkan oleh uap tar yang terkandung dalam volatile matter akan menjadi reaktif. Uap tar dapat mengalami reaksi sekunder berupa cracking menjadi gas-gas hidrokarbon yang terperangkap di dalam pori-pori partikel arang atau mengalami repolimerisasi menjadi arang. Untuk bahan campuran, benda uji 4 (bambu daun pisang) memiliki energi aktivasi terendah yaitu 22,923 (kJ/mol). Karakteristik pembakaran pada benda uji 4 yaitu ITVM $=158^{\circ} \mathrm{C}$, ITFC $=176$ ${ }^{\circ} \mathrm{C}, \mathrm{PT}=376{ }^{\circ} \mathrm{C}$ dan $\mathrm{BT}=729^{\circ} \mathrm{C}$.

\section{Daftar pustaka}

Di Blasi, C. ,2008, Modeling Chemical and Physical Processes of Wood and Biomass Pyrolisis, Progress in Energy and Combustion Science 34 , pp. 47-99

Grammelis,P., Basinas, P., Malliopoulou, A., Sakellaropoulos, G., 2009, Pyrolisis Kinetics and Combustion Characteristics of Waste Recovered Fuels, Fuel 88 (2009), pp. 195-205

Gran, I.R., 2001, "Characterisation of MSW for Combustion Systems", SINTEF Energy Research, Norway.

Ojolo,S.J dan Bamgboye,2005 ,Thermochemical Conversion of Municipal Solid Waste to Produce Fuel and Reduce WasteAgricultural Engineering International: the CIGR Ejournal. Vol. VII. Manuscript EE 05 006. September, 2005. 
Phan, AN, Ryu, C., Sharifi, V.N., Swithenbank, J., 2008, Characterisation of Slow Pyrolisis Products from Segregated Wastes for Energy Production,

J.Anal.Appl.Pyrolisis 81 (2008), pp. 65-71.

Saptoadi, H., 2006, The Best Biobriquette Dimension and its Particle Size, The 2nd Joint
International Conference on "Sustainable Energy and Environment (SEE 2006)" 2123 November, Bangkok, Thailand.

Zapusek, A., Wirtgen, C., Weigandt, J. dan Lenart, F., 2003, Characterisation of Carbonizate Produced from Velenje Lignite In Lab-Scale Reactor, Acta Chim. Slov.50, 789 $\square 798$. 